\title{
Takotsubo cardiomyopathy in a patient with bipolar disorder
}

\author{
Dominika M Zoltowska, ${ }^{1}$ Jagadeesh K Kalavakunta, ${ }^{2}$ Prem S Subramaniyam, ${ }^{3}$ \\ William F Lapenna ${ }^{4}$
}

${ }^{1}$ Internal Medicine, Western Michigan University School of Medicine, Kalamazoo, Michigan, USA

${ }^{2}$ Cardiology, Borgess Medical Center/Michigan State University/Western Michigan University School of Medicine, Kalamazoo, Michigan, USA ${ }^{3}$ Cardiology, Borgess Medical Center, Kalamazoo, Michigan, USA

${ }^{4}$ Cardiology, Borgess Medical Center, Kalamazoo, Michigan, USA

\section{Correspondence to} Dr Dominika M Zoltowska, dominika.zoltowska@med. wmich.edu

Accepted 1 August 2018

\section{DESCRIPTION}

A 48-year-old woman, with medical history of bipolar disorder and no previous cardiovascular disease, presented to the emergency department with acute onset of typical angina. Pain improved with sublingual nitroglycerin, but did not resolve completely. She reported to have similar brief episodes of self-resolving chest pain for the last 2 weeks, which she interpreted as panic attacks. Her home medications included lamotrigine $100 \mathrm{mg}$ and paroxetine $20 \mathrm{mg}$ started many years ago. Her lab results were significant for elevated troponin at $5.5 \mathrm{ng} / \mathrm{mL}$ and normal thyroid-stimulating hormone level. ECG did not show any acute ischaemic changes. Subsequently, the patient underwent coronary angiography, which did not show any obstructive coronary disease (figure 1), but left ventriculogram showed mildly reduced ejection fraction of $45 \%$ and mid-ventricular ballooning (video1). Further course of admission was not complicated. The patient was treated conservatively with resolution of symptoms. Follow-up transthoracic echocardiogram 4 weeks after discharge showed complete recovery of systolic function.

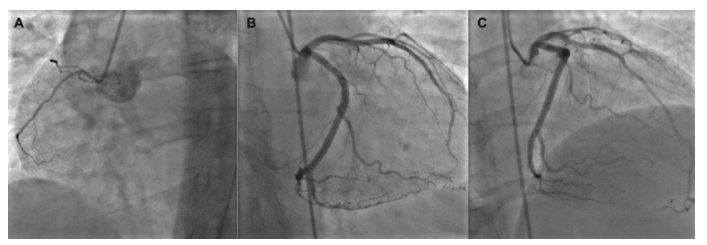

Figure 1 Coronary angiogram: (A) left anterior oblique cranial view, (B) right anterior oblique caudal view and (C) right anterior oblique cranial view.

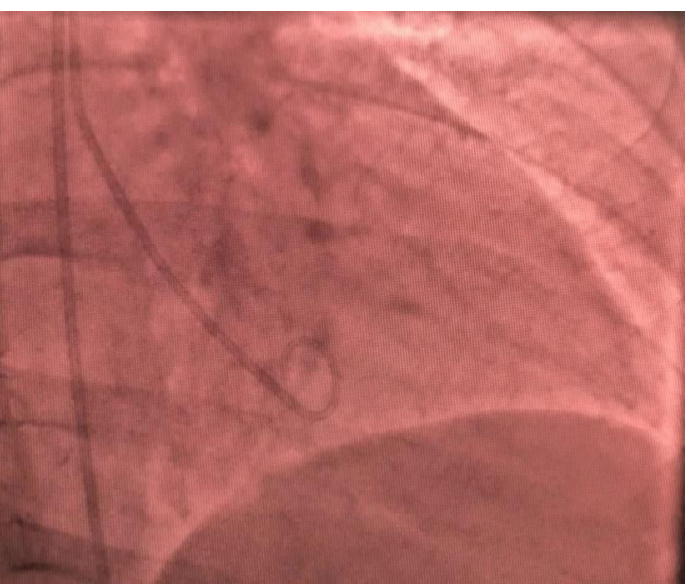

Video 1 Left ventriculogram.
The above case presents a mid-ventricular variant of Takotsubo cardiomyopathy (TCM). The diagnosis was made based on the characteristic findings on left ventriculogram, after exclusion of ischaemic heart disease. ${ }^{1}$

The incidence of TCM is highest in postmenopausal women, which grossly corresponds to our case. Traditionally, the disease is evoked by a strong emotional stressor. Our patient did not report any specific triggers; however, she felt anxious for the last 2 weeks before admission. Regarding these symptoms, thyroid function tests were performed. Both hyperthyroidism and hypothyroidism are known to cause cardiomyopathy and were previously reported as potential risk factors for TCM. ${ }^{2}$

Bipolar disorder comprises an interesting point of our patient's medical history. Evidence obtained from a large retrospective study implies strong association of psychiatric disorders with TCM. ${ }^{3}$ Moreover, patients with psychiatric or neurological diseases are more prone to develop serious adverse events during an admission. Interestingly, lithium and electroconvulsive therapy, commonly used for treatment of bipolar disorder, have been reported to cause acute cardiomyopathy. This is an unknown complication of our patient's medications, lamotrigine and paroxetine. It is still not determined what is the long-term prognosis and recurrence risk for this patient population, and it remains unclear what is the significance of good disease control for secondary prevention.

\section{Learning points}

- Exclusion of ischaemic heart disease before making the diagnosis of Takotsubo cardiomyopathy (TCM) is important.

- Mid-ventricular ballooning is an atypical pattern of TCM.

- There is an association between psychiatric diseases and TCM.

Contributors DMZ, JKK, PSS and WFL were the physicians in charge of the patient throughout hospitalisation and follow-up. DMZ, JKK, PSS and WLF were responsible for performing, diagnosing and discussing the imaging studies of the patient. DMZ prepared the manuscript draft, which was critically revised by WLF and approved by all authors.

Funding The authors have not declared a specific grant for this research from any funding agency in the public, commercial or not-for-profit sectors.

Competing interests None declared.

Patient consent Obtained. 
Provenance and peer review Not commissioned; externally peer reviewed.

\section{REFERENCES}

1 Scantlebury DC, Prasad A. Diagnosis of Takotsubo cardiomyopathy. Circ J 2014;78:2129-39.
2 Zoltowska D, Agrawal Y, Patri S, et al. Association between hypothyroidism and takotsubo cardiomyopathy: analysis of nationwide inpatient sample database. Rev Recent Clin Trials 2018;13.

3 Templin C, Ghadri JR, Diekmann J, et al. Clinical features and outcomes of takotsubo (Stress) cardiomyopathy. N Engl J Med 2015;373:929-38.

Copyright 2018 BMJ Publishing Group. All rights reserved. For permission to reuse any of this content visit http://group.bmj.com/group/rights-licensing/permissions.

BMJ Case Report Fellows may re-use this article for personal use and teaching without any further permission.

Become a Fellow of BMJ Case Reports today and you can:

- Submit as many cases as you like

- Enjoy fast sympathetic peer review and rapid publication of accepted articles

- Access all the published articles

- Re-use any of the published material for personal use and teaching without further permission

For information on Institutional Fellowships contact consortiasales@bmjgroup.com

Visit casereports.bmj.com for more articles like this and to become a Fellow 